\title{
All about Accommodative Esotropia
}

\section{Partha Haradhan Chowdhury ${ }^{1 *}$, Brinda Haren Shah ${ }^{2}$ and Nripesh}

\section{Tiwari ${ }^{3}$}

${ }^{1}$ M.Optom, Associate Professor, Principal, Department of Optometry, Shree Satchandi

\section{Short Communication}

Volume 3 Special Issue 1

Received Date: September 18, 2018

Published Date: October 08, 2018

Jankalyan Samiti Netra Prasikshan Sansthan, Pauri, Affiliated to Uttarakhand State Medical Faculty, Dehradun, India 2M.Optom, Guest Lecturer, Department of Optometry, Shree Satchandi Jankalyan Samiti Netra Prasikshan Sansthan, Pauri, Affiliated to Uttarakhand State Medical Faculty, Dehradun, India

${ }^{3}$ D.Optom, General Secretary and Chief Optometrist, Department of Optometry, Shree Satchandi Jankalyan Samiti Netra Prasikshan Sansthan, Pauri, Affiliated to Uttarakhand State Medical Faculty, Dehradun, India

*Corresponding author: Partha Haradhan Chowdhury, M. Optom, Associate Professor, Principal, Department of Optometry, Shree Satchandi Jankalyan Samiti Netra Prasikshan Sansthan, Pauri, Affiliated to Uttarakhand State Medical Faculty, Dehradun, India, Email: optometrypublish@gmail.com

\section{Abstract}

This paper describes about accommodative esotropia, its clinical features and its treatment.

Keywords: Accommodative Esotropia; Partially Accommodative Esotropia

\section{Introduction}

Accommodative Esotropia is usually associated with Hypermetropic Refractive error, so it is also known as "Refractive Esotropia" or "Hypermetropic Esotropia". Most of the time it is associated with $+2.00 \mathrm{D}$ or more than or upto $+6.00 \mathrm{D}$. Accommodative Esotropia is mostly associated with High $\mathrm{AC} / \mathrm{A}$ ratio, i.e.in case of High $\mathrm{AC} / \mathrm{A}$ ratio, there is a variation between distance and near ocular deviation. In case of high $\mathrm{AC} / \mathrm{A}$ ratio, there is more ocular deviation at near as compared to distance. Eye will be more convergent at near than distance deviation. So, it shows that eye accommodates more at near as compared to distance. This type of deviation needs urgent consultation in proper time otherwise eye will be amblyopic. Accommodative Esotropia usually presents as intermittent stages initially but due to low fusional vergence and other reasons, it becomes Accommodative Esotropia [1-3].

\section{Clinical Features}

Usually, it is present from infancy to late childhood stages. Always cycloplegic refraction should be performed and its dosage should be dependent on the patient's age. Cycloplegic Refraction reveals that patient is hypermetropic and its range is $+1.50 \mathrm{D}$ to $+6.50 \mathrm{D}$. In this case, patient is always instructed to look at Accommodative target and follow the ocular deviation. Complaint of parents will be during near work and tiredness, child's eyes are cross.

\section{Treatment}

Cycloplegic Refraction should be performed and full amount of correction should be given. In case, $\mathrm{AC} / \mathrm{A}$ ratio is high after full correction, then bifocal spectacles should be given. Cut section of the bifocal lens should be placed in front of the pupil to maintain accommodation. Child should be advised to wear glasses intermittently than constantly. Atropine should be advised in serious cases when patient is getting problems with spectacles [4]. 


\section{Open Access Journal of Ophthalmology}

If ocular deviation is within $10 \mathrm{PD}$ with spectacle correction it is a normal condition. If ocular deviation is more than 10 PD for distance and near instead of wearing spectacles for more than 6 to 8 weeks, Medial Rectus muscle recession should be done. This is called Partially Accommodative Esotropia. Bilateral MR Recession is an indicative factor [5].

\section{References}

1 Kenneth W Wright, Peter H Spiegel (2003) Pediatric Ophthalmology and Strabis-mus. $2^{\text {nd }}$ (Edn.).
2 Kenneth W Wright, Peter H Spiegel, Lisa Thompson (2006) Handbook of Pediatric Strabismus and Amblyopia.

3 Kenneth W Wright (2007) Color Atlas of Strabismus Surgery: Strategies and Techniques.

4 Theodore G, Theodore P (2007) Primary Care Optometry. $5^{\text {th }}$ (Edn.).

5 Mitchell S, Bruce W (2008) Clinical Management of Binocular Vision. $3^{\text {rd }}$ (Edn.). 